\title{
Percepção de puérperas quanto às boas práticas de assistência ao trabalho de parto e parto
}

\section{Postpartum women's perspectives on the quality of labor and delivery care}

Andressa Soares de Azevedo ${ }^{1}$. Mayle Andrade Moreira ${ }^{1}$. Sabrina Dantas Sabry ${ }^{2}$. Úrsula Maria Lima Pessoa ${ }^{1}$. Elisete Mendes Carvalho ${ }^{1,3}$. Simony Lira do Nascimento ${ }^{1}$.

1 Universidade Federal do Ceará (UFC), Fortaleza, Ceará, Brasil. 2 Faculdade Ateneu (Fate), Faculdade Rodolfo Teófilo (FRT), Fortaleza, Ceará, Brasil. 3 Maternidade Escola Assis Chateaubriand (HUWC), Fortaleza, Ceará, Brasil.

\section{RESUMO}

Objetivo: Verificar a aplicação das diretrizes de assistência ao parto humanizado e analisar a percepção das puérperas quanto às boas práticas de assistência ao trabalho de parto (TP) e nascimento em uma maternidade pública de referência em Fortaleza - CE. Metodologia: Estudo transversal e quantitativo com 110 puérperas após parto vaginal hospitalar, a termo e com feto único. A entrevista foi através de questionário estruturado sobre direitos, boas práticas, utilização de métodos não-farmacológicos para alívio da dor e satisfação quanto à assistência ao TP e nascimento. Resultados: $100 \%$ estavam acompanhadas durante o TP e $72,7 \%$ tiveram parto na maternidade por livre escolha, no entanto, apenas 30\% visitaram a maternidade previamente. A liberdade de escolha de posição no TP e o contato pele a pele alcançaram 95,4\% da amostra. A episiotomia ocorreu em apenas 5,4\% e a manobra de Kristeller ainda foi reportada por 16,3\% das mulheres. As medidas não-farmacológicas foram amplamente utilizadas, sendo as mais prevalentes o banho de chuveiro $(77,2 \%)$, os exercícios respiratórios $(75,4 \%)$ e a movimentação na bola suíça (71,8\%). Conclusão: O estudo revelou a aplicação das diretrizes de assistência ao parto humanizado e um alto grau de satisfação entre as mulheres assistidas.

Palavras-chave: Trabalho de parto. Parto obstétrico. Parto humanizado.

\section{ABSTRACT}

Objective: To verify the use of the guidelines to humanized childbirth and to analyze puerperal women's perceptions regarding good practices of attention to labor and delivery in a tertiary public maternity. Methods: A cross-sectional study included 110 post-partum women who had hospital vaginal delivery, at term and single fetus. The instrument contained closed questions about the rights of the mother, good care practices, non-pharmacological methods of pain relief and woman's satisfaction. Results: $100 \%$ had a companion during labour and $72.7 \%$ had a birth in the maternity by free choice, however, only $30 \%$ had the opportunity to visit the maternity ward previously. We observed that the freedom of choice of position during labour and skin-to-skin contact reached $95.4 \%$ of the sample. Episiotomy was performed in only 5.4\% and the use of the Kristeller maneuver was still reported by $16.3 \%$ of the women. Non-pharmacological measures for pain relief were widely used. Shower bath $(77,2 \%)$, breathing exercises (75.4\%) and movement in the Swiss ball (71.8\%) were the most prevalent. Conclusion: The study revealed the application of guidelines for assistance to humanized childbirth and a high degree of satisfaction among women assisted.

Keywords: Labor, obstetric. Obstetric delivery. Humanized delivery.

Autor correspondente: Andressa Soares de Azevedo, Avenida Augusto dos Anjos, 312, Jóckey, Fortaleza, Ceará. CEP: 60520-022. Telefone: +55 85 99636-2954. E-mail: andressa_azevedo@live.com

Conflito de interesses: Não há qualquer conflito de interesses por parte de qualquer um dos autores.

Recebido em: 08 Fev 2019; Revisado em: 24 Abr 2019; Aceito em: 09 Jun 2019. 


\section{INTRODUÇÃO}

O parto é um evento envolvido por fatores muito além dos fisiológicos, sendo influenciado pelos valores sociais, culturais, emocionais e afetivos. ${ }^{1}$

Culturalmente, o parto ocorria principalmente em ambiente domiciliar. As gestantes eram assistidas por parteiras e o trabalho de parto seguia seu curso natural. Contudo, não havia assistência especializada para possíveis intercorrências. ${ }^{2}$

Com a finalidade de obter maior segurança, o nascimento no meio hospitalar é marcado pelo uso de técnicas e tecnologias. Apesar da melhoria nos níveis de morbimortalidade materna e perinatais, o trabalho de parto e nascimento tornaram-se mecanizados, sendo representados na maioria das vezes como uma patologia e não como um evento fisiológico. ${ }^{3}$ Como consequência disso, as taxas de cesárea aumentaram tanto nos países desenvolvidos quanto em desenvolvimento. ${ }^{4}$ Segundo a Organização Mundial de Saúde, o Brasil é líder mundial de cesáreas, atingindo uma taxa de cerca de $55 \%$, sendo entre 10 $15 \%$ o recomendado desde $1985.5,6$

Na busca pelo constante aprimoramento da assistência em saúde, em junho de 2011 foi lançado o novo programa nacional de assistência obstétrica e infantil, a Rede Cegonha. Elaborado pelo Ministério da Saúde, abrange uma rede de assistência à mulher e ao recém-nascido, cuja finalidade é diminuir os óbitos maternos e neonatais. Esse programa busca incentivar o parto normal e impulsionar as maternidades a aplicarem as boas práticas de assistência ao parto e ao nascimento. ${ }^{7}$

A Maternidade Escola Assis Chateaubriand (MEAC), unidade de referência materno-infantil no estado do Ceará, aderiu à Rede Cegonha em 2012 e implantou as diretrizes propostas pelo programa. ${ }^{7}$ Em agosto de 2016, a maternidade recebeu do Ministério da Saúde o reconhecimento como o primeiro Centro de Apoio ao desenvolvimento das boas práticas de atenção obstétrica e neonatal no país. ${ }^{8}$

Nesse contexto de um novo modelo de atenção, pesquisas são necessárias para retratar o impacto da aplicação das boas práticas de assistência. Como principal sujeito desse novo padrão assistencial, a percepção das puérperas se constitui como importante parâmetro de desfecho dessas práticas através do atendimento recebido.

Assim, este estudo possui o objetivo de verificar a aplicação das diretrizes ao parto humanizado na referida maternidade e analisar a percepção das puérperas quanto às boas práticas de assistência ao trabalho de parto e nascimento.

\section{MATERIAIS E MÉTODOS}

O estudo possui desenho transversal, quantitativo e descritivo, conduzido mediante consulta aos prontuários e análise de questionário fechado (elaborado pelas próprias pesquisadoras) aplicado com puérperas de parto vaginal internadas nas enfermarias obstétricas da MEAC.
A seleção da amostra foi do tipo não probabilística, por conveniência. Os critérios de inclusão foram puérperas de gestação única, de parto vaginal hospitalar a partir de 37 semanas, entre 12 e 72 horas pós-parto. Os critérios de exclusão foram puérperas internadas na Unidade de Terapia Intensiva (UTI) e com déficit cognitivo. A coleta de dados ocorreu do período de 20 de julho a 30 de setembro de 2016.

O questionário foi elaborado de acordo com as propostas da Rede Cegonha. Tal Programa possui como uma de suas diretrizes a "garantia das boas práticas de assistência e segurança na atenção ao parto e nascimento". Essas práticas devem ser baseadas em evidências científicas nos termos do documento da Organização Mundial da Saúde (OMS) de classificação das práticas no parto normal desenvolvido em 1996. ${ }^{9}$

A coleta foi realizada por uma única pesquisadora com o objetivo de padronização da entrevista. O questionário aplicado era composto por 26 perguntas, baseadas nas diretrizes de boas práticas de assistência ao trabalho de parto e nascimento do Ministério da Saúde.

As perguntas abordavam temas como dados sociodemográficos (idade, faixa etária, grau de escolaridade e ocupação), oportunidade de visita à maternidade em questão, livre escolha do local para parir, direito a acompanhante da preferência da gestante no trabalho de parto e no nascimento, acesso a medidas alternativas para alívio da dor e de auxílio na progressão do trabalho de parto, procedimentos devidamente explicados no trabalho de parto e nascimento, escolha da posição para trabalho de parto e nascimento, intervalo entre os exames de toque, ocorrência de comentários ofensivos, manobra de Kristeller, episiotomia, clampeamento do cordão umbilical, contato pele a pele no primeiro minuto, amamentação na primeira hora, profissionais que prestaram assistência, satisfação e classificação do atendimento recebido. O preenchimento desse instrumento com as puérperas teve duração de cerca de 15 minutos.

$\mathrm{Na}$ consulta aos prontuários foram observados os seguintes dados: idade gestacional, paridade, data do parto, apresentação do feto, profissional que prestou assistência ao parto (médico ou enfermeiro), preenchimento do partograma, uso de fórceps, realização de episiotomia e ocorrência e grau de laceração perineal.

Os dados coletados foram tabulados em banco de dados no Excel e a análise estatística descritiva realizada através do programa Epi-Ifo versão7. A normalidade dos dados foi testada pelo teste Shapiro Wilk. A descrição dos dados nominais foi realizada por meio de número absoluto e porcentagem; e das variáveis contínuas em média e desvio padrão.

Os resultados foram comparados com as diretrizes propostas pela OMS, que classifica as práticas em demonstradamente úteis e que devem ser estimuladas (categoria A), claramente prejudiciais ou ineficazes e que devem ser eliminadas 
(categoria B), sem evidências suficientes para apoiar uma recomendação clara e que devem ser utilizadas com cautela até que mais pesquisas esclareçam a questão (categoria $\mathrm{C}$ ) e frequentemente usadas de modo inadequado (categoria D). ${ }^{9}$

Além disso, os resultados foram analisados considerando a Portaria número 353, de 14 de fevereiro de 2017 sobre as Diretrizes Nacionais de Assistência ao Parto Normal propostas pelo Ministério da Saúde e elaboradas por uma equipe multidisciplinar, onde recebeu contribuições por meio de consulta pública, composta em sua maioria (87\%) por mulheres. ${ }^{10}$

O estudo obedeceu aos princípios éticos previstos na resolução 466/2012 do Conselho Nacional de Saúde. Realizada após parecer favorável (CAAE 57207916.0.0000.5050) do Comitê de Ética em Pesquisa da MEAC, a coleta de dados ocorreu somente após a leitura e assinatura do termo de consentimento livre e esclarecido pelo sujeito da pesquisa.

\section{RESULTADOS}

Foram incluídas na pesquisa 110 puérperas. A maioria possuía faixa etária de 18 a 25 anos (Tabela 1). Apenas 30,9\% tiveram a oportunidade de visitar a maternidade previamente e todas tiveram direito a acompanhante (Gráfico 1).

Tabela 1. Características sociodemográficas das puérperas incluídas no estudo.

\begin{tabular}{|c|c|c|}
\hline Característica & $\begin{array}{l}\text { Média } \\
\mathrm{n}=110\end{array}$ & $\begin{array}{l}\text { Desvio } \\
\text { padrão }\end{array}$ \\
\hline \multirow[t]{2}{*}{ Idade } & 22,1 & 5,8 \\
\hline & $\mathbf{n}$ & $\%$ \\
\hline \multicolumn{3}{|l|}{ Faixa etária } \\
\hline$<18 \mathrm{a}$ & 19 & 17,2 \\
\hline 18 a 25 a & 70 & 63,6 \\
\hline 26 a 35 a & 17 & 15,4 \\
\hline$\geq 36 \mathrm{a}$ & 4 & 3,64 \\
\hline \multicolumn{3}{|l|}{ Cor } \\
\hline Branca & 14 & 12,7 \\
\hline Amarela & 5 & 4,5 \\
\hline Parda & 82 & 74,5 \\
\hline Negra & 9 & 8,1 \\
\hline \multicolumn{3}{|l|}{ Escolaridade } \\
\hline Fundamental & 44 & 40 \\
\hline Médio completo & 64 & 58,1 \\
\hline Superior completo & 2 & 1,8 \\
\hline \multicolumn{3}{|l|}{ Ocupação } \\
\hline Estudante & 16 & 14,5 \\
\hline Trabalho remunerado & 31 & 28,1 \\
\hline Do lar/outros & 63 & 57,2 \\
\hline
\end{tabular}

Gráfico 1. Direitos legais das mulheres durante o trabalho de parto e parto conforme a Rede Cegonha.

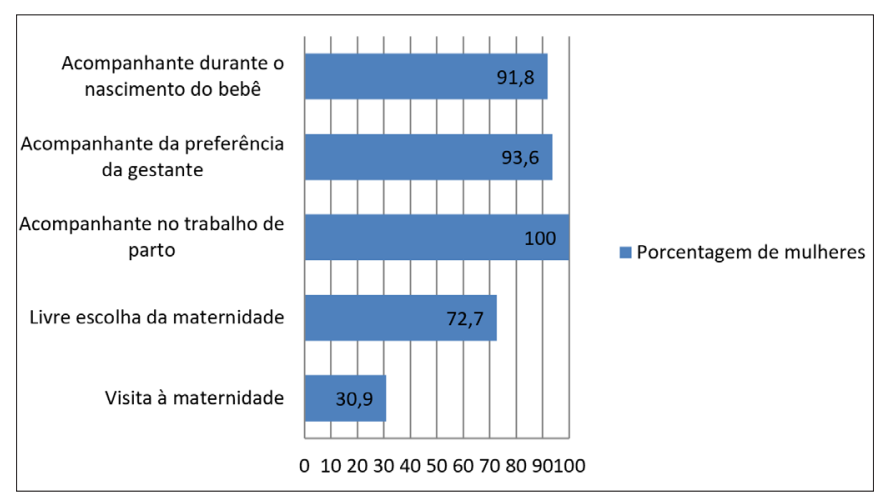

A maioria das mulheres $(54,6 \%)$ era primigesta (Tabela 2) e $87,2 \%$ das mulheres tiveram acesso a medidas não farmacológicas para alívio da dor (Gráfico 2). Relacionado à percepção das puérperas diante das condutas (Tabela 3), seis puérperas relataram terem sido alvo de comentários ofensivos. A liberdade de escolha de posição no TP e o contato pele a pele alcançaram 95,4\% da amostra. A episiotomia ocorreu em apenas $5,4 \%$ e a manobra de Kristeller foi reportada por $16,3 \%$ das mulheres.

O atendimento foi classificado como excelente por 72 mulheres. Nenhuma puérpera classificou o atendimento como ruim.

Tabela 2. Informações obstétricas e reprodutivas das puérperas incluídas no estudo.

\begin{tabular}{lcc}
\hline \multicolumn{1}{c}{ Variáveis } & n & \% \\
\hline Gestações & 59 & 54,6 \\
Primigesta & 27 & 25 \\
2 & 13 & 12,1 \\
3 & 9 & 8,3 \\
$\geq 4$ & & \\
Paridade & 61 & 56,4 \\
$\quad$ Primípara & 47 & 43,5 \\
Multípara & 1,8 & 1,2 \\
Idade gestacional no parto (média - & 43 & 40,1 \\
DP) & & 54,2 \\
37-38 semanas & 58 & 5,6 \\
39-40 semanas & 6 & \\
41 semanas & & \\
Apresentação fetal & 107 & 97,2 \\
Cefálico & 3 & 2,7 \\
Pélvico & & \\
Uso de fórceps & 105 & 95,4 \\
sim & & \\
não & 109 & 99 \\
Episiotomia & & \\
sim & & \\
não & 5 & 4,5 \\
\hline
\end{tabular}

Continua. 
Conclusão.

Tabela 2. Informações obstétricas e reprodutivas das puérperas incluídas no estudo.

\begin{tabular}{lcc}
\hline \multicolumn{1}{c}{ Variáveis } & $\mathbf{n}$ & $\mathbf{\%}$ \\
\hline Laceração & 72 & 66,6 \\
sim & 36 & 33,3 \\
não & & \\
Grau da laceração & 26 & 40 \\
1 & 36 & 55,3 \\
2 & 3 & 4,6 \\
3 & & \\
Preenchimento do partograma & 108 & 98,1 \\
sim & 2 & 1,8 \\
não & & \\
Profissional que prestou assistência & & \\
$\quad$ enfermeiro & 38 & 35,8 \\
médico & 71 & 66,9 \\
\hline
\end{tabular}

Gráfico 2. Relato das puérperas quanto à utilização de medidas não farmacológicas para alívio da dor durante o trabalho de parto.

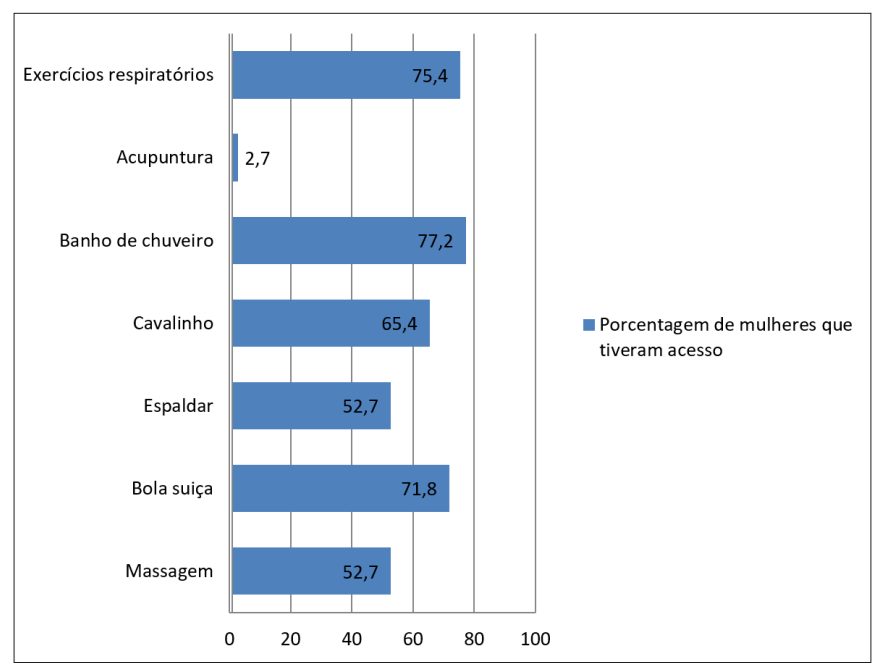

Tabela 3. Percepção das puérperas diante das condutas indicadas pela Rede Cegonha e avaliação da satisfação quanto ao atendimento durante o trabalho de parto e parto.

\begin{tabular}{lcc}
\hline \multicolumn{1}{c}{ Conduta } & $\mathbf{n}$ & $\mathbf{\%}$ \\
\hline Ingestão de líquidos durante TP & & \\
sim & 96 & 87,2 \\
não & 14 & 12,7 \\
Escolha da posição durante TP & & \\
$\quad$ sim & 105 & 95,4 \\
não & 5 & 4,5 \\
Escolha da posição durante o nascimento & & \\
sim & 73 & 66,3 \\
não & 37 & 33,6 \\
\hline
\end{tabular}

Continua.
Conclusão.

Tabela 3. Percepção das puérperas diante das condutas indicadas pela Rede Cegonha e avaliação da satisfação quanto ao atendimento durante o trabalho de parto e parto.

\begin{tabular}{|c|c|c|}
\hline Conduta & n & $\%$ \\
\hline \multicolumn{3}{|c|}{$\begin{array}{l}\text { Incômodo pela frequência do exame de } \\
\text { toque }\end{array}$} \\
\hline $\operatorname{sim}$ & 13 & 11,8 \\
\hline não & 97 & 88,1 \\
\hline \multicolumn{3}{|l|}{ Comentários ofensivos } \\
\hline $\operatorname{sim}$ & 6 & 5,4 \\
\hline não & 104 & 94,5 \\
\hline \multicolumn{3}{|c|}{ Procedimentos explicados durante TP } \\
\hline $\operatorname{sim}$ & 105 & 95,4 \\
\hline não & 5 & 4,5 \\
\hline \multicolumn{3}{|c|}{ Procedimentos durante o nascimento } \\
\hline $\operatorname{sim}$ & 103 & 93,6 \\
\hline não & 7 & 6,3 \\
\hline \multicolumn{3}{|l|}{ Manobra de Kristller } \\
\hline $\operatorname{sim}$ & 18 & 16,3 \\
\hline não & 92 & 83,6 \\
\hline \multicolumn{3}{|l|}{ Episiotomia } \\
\hline $\operatorname{sim}$ & 6 & 5,4 \\
\hline não & 104 & 94,5 \\
\hline \multicolumn{3}{|l|}{ Pergunta sobre a episiotomia } \\
\hline $\operatorname{sim}$ & 5 & 4,5 \\
\hline não & 1 & 0,9 \\
\hline
\end{tabular}

Clampeamento precoce do cordão umbilical

$\begin{array}{lll}\operatorname{sim} & 13 & 11,8 \\ \text { não } & 97 & 88,1\end{array}$

Contato pele a pele no primeiro minuto

$$
\begin{array}{lcc}
\text { sim } & 105 & 95,4 \\
\text { não } & 5 & 4,5
\end{array}
$$

Amamentação na primeira hora

$\begin{array}{lll}\text { sim } & 79 & 71,8 \\ \text { não } & 31 & 28,1\end{array}$

Reconhecimento do profissional que prestou assistência

$\begin{array}{lcc}\text { médico } & 90 & 81,8 \\ \text { enfermeiro } & 104 & 94,5 \\ \text { fisioterapeuta } & 1 & 0,9\end{array}$

outros

Classificação da satisfação quanto ao atendimento

\begin{tabular}{lcc} 
Excelente & 72 & 65,5 \\
Bom & 35 & 31,8 \\
Regular & 3 & 2,7 \\
Ruim & 0 & - \\
\hline
\end{tabular}




\section{DISCUSSÃO}

Os resultados do presente estudo demonstraram a aplicação das boas práticas de assistência ao trabalho de parto e parto através da visão das puérperas atendidas na MEAC, gerando assim um alto grau de satisfação entre essas mulheres.

Na referida maternidade, $72,7 \%$ das mulheres direcionaram-se à instituição por livre escolha para a realização do parto. Esse dado é bastante incentivador e demonstra respeito à escolha da gestante para o local do parto, sendo esta prática classificada como categoria A pela OMS. Além disso, todas as mulheres tiveram direito a acompanhante. Este é assegurado pela Lei $\mathrm{n}^{\mathrm{o}} 11.108 / 2005$, art. 19:

"Os serviços de saúde do Sistema Único de Saúde - SUS, da rede própria ou conveniada, ficam obrigados a permitir a presença, junto à parturiente, de um (1) acompanhante durante todo o período de trabalho de pré-parto, parto e pós-parto imediato. O acompanhante de que trata o caput deste artigo será indicado pela parturiente." 11

Dessa forma, além do direito a acompanhante, faz-se necessário que este seja da preferência da parturiente, independente de sexo.

Uma das questões que mais influenciam na experiência da mulher no evento do parto é a dor e seu manejo. As Diretrizes propostas pelo Ministério da Saúde ressaltam que medidas não farmacológicas para alívio da dor devem ser ofertadas às mulheres antes dos meios farmacológicos.

O estudo de Davim, Torres e Dantas (2009), ${ }^{12}$ realizado em uma maternidade pública do Rio Grande do Norte com 100 mulheres, constatou diferença significativa nos graus de dor antes $(6,4$ a 9,9) e após aplicação $(4,4$ a 8$)$ de estratégias não farmacológicas para alívio da dor $(\mathrm{p}=0,000)$. Em nossa pesquisa, $87,2 \%$ das puérperas informaram que tiveram acesso a estratégias para diminuição da dor durante o trabalho de parto. A medida mais utilizada em nosso estudo foi o banho de chuveiro, onde $87,2 \%$ das mulheres puderam usufruir dessa estratégia. Ainda no estudo de Davim e seus colaboradores, foi verificado que o banho possui efetivo alívio da dor das parturientes, proporcionando redução da sensação dolorosa e consequente relaxamento. As Diretrizes Nacionais introduzidas em $2017^{10}$ propõem inclusive que gestores nacionais e locais devem proporcionar condições para a modificação das unidades de assistência ao parto para que seja possível a oferta de imersão em água às parturientes.

Um outro direito das parturientes, segundo a OMS, é ter acesso a explicações e informações em trabalho de parto, parto e pós-parto, conforme sua necessidade e desejo. ${ }^{9}$ Neste estudo, a maioria das puérperas relatou que os procedimentos eram devidamente explicados a elas durante o trabalho de parto e o parto. O estudo de Silva, Nascimento e Coelho $(2015)^{13}$ ressalta que favorecer o acesso a informações gera empoderamento nas parturientes, possibilitando assim o desenvolvimento de conhecimentos e atitudes para a participação ativa nas decisões relacionadas a sua saúde. Uma das oportunidades de incrementar o conhecimento da família sobre os procedimentos do parto é durante visita a maternidade de referência, fato que ocorreu em apenas um terço dessa amostra, demonstrando que muitas vezes a mulher não conhece o ambiente da maternidade. No entanto, vale ressaltar que a maternidade atende público de alto risco, sendo algumas mulheres encaminhadas de outros centros apenas no momento do trabalho de parto.

A oferta de alimentos foi outra questão observada em nosso estudo. Segundo a revisão de literatura de Porto, Amorim e Souza, ${ }^{14}$ o jejum não é recomendado em pacientes de baixo nem de alto risco. Além disso, a OMS recomenda a oferta de líquidos por via oral às mulheres durante o trabalho de parto e parto. As novas diretrizes de assistência ao parto normal também recomendam que as mulheres que não estiverem sob uso de opioide ou não apresentem indicador de risco para anestesia geral podem ter acesso a dieta leve. Em nossa pesquisa, a maioria das mulheres $(87,2 \%)$ pôde tomar líquidos durante o trabalho de parto.

Um dos maiores medos das gestantes quanto ao parto está relacionado aos exames vaginais. A OMS classifica a alta frequência desses exames (principalmente se for por mais de um profissional) como uma prática de categoria D. Mesmo assim, a alta frequência dessa prática ainda é bastante recorrente nas maternidades. De acordo com as Diretrizes Nacionais de 2017, o exame vaginal deve ser realizado de 4 em 4 horas no primeiro período do trabalho de parto. $\mathrm{Na}$ presente pesquisa, 13 mulheres relataram terem sentindo incômodo quanto à frequência desse exame.

Com relação ao apoio empático dos profissionais envolvidos, de acordo com a Política Nacional de Atenção Obstétrica e Neonata ${ }^{15}$ "toda gestante tem direito à assistência ao parto e ao puerpério e que essa seja realizada de forma humanizada e segura". Nesta pesquisa, apenas seis $(5,4 \%)$ puérperas relataram se sentirem ofendidas por comentários realizados pelos prestadores de serviço durante a assistência. Esse resultado assemelha-se ao estudo de Motta et. al. (2016), ${ }^{16}$ sobre a implementação da humanização da assistência ao parto natural em um hospital secundário municipal de Fortaleza pertencente à Rede Cegonha, onde apenas 4 das 51 mulheres da pesquisa informaram não ter recebido esse apoio adequadamente.

Quanto à liberdade de posição e movimento durante o trabalho de parto, a OMS classifica como uma prática categoria A. ${ }^{16} \mathrm{As}$ Diretrizes Nacionais de 2017 também propõem o estímulo dos profissionais às mulheres para que se movimentem e adotem posições que sejam mais confortáveis a elas. De acordo com os indicadores da instituição ${ }^{17}$ onde foi realizada a presente pesquisa, $100 \%$ das mulheres assistidas de janeiro a julho de 2016 foram estimuladas a parir em posição não horizontal. Os dados coletados na pesquisa confrontam esse resultado a partir da percepção das puérperas assistidas, pois cinco referiram não ter esse poder de escolha durante o trabalho de parto e 37 durante o nascimento.

Uma prática bastante temida entre as parturientes é a manobra de Kristeller. As Diretrizes do Ministério da Saúde não 
recomendam essa manobra no segundo período do trabalho de parto. O estudo de Sousa (2013) ${ }^{18}$ em uma maternidade em Belo Horizonte verificou a ocorrência dessa manobra em $11,5 \%$ das 90 participantes de sua pesquisa. Verifica-se essa prática como ainda recorrente nas instituições. Neste estudo, $16,3 \%$ das puérperas informaram terem passado por esse procedimento, demonstrando um índice ainda elevado de ocorrência.

Outra prática que causa bastante receio entre as mulheres é a realização da episiotomia durante o parto. As Diretrizes recomendam a não realização de episiotomia de rotina durante o parto vaginal espontâneo. No caso da necessidade de realização, a indicação deve ser justificada e a parturiente deve receber analgesia efetiva antes do procedimento. Além disso, o Ministério da Saúde recomenda a solicitação de permissão à parturiente antes de qualquer procedimento, devendo a mulher ser o foco principal e não o uso da tecnologia ou documentação. Das seis mulheres que realizaram episiotomia nesta pesquisa, apenas uma informou não ter sido questionada sobre a permissão para realização do procedimento. Diferentemente, em uma maternidade pública em Santa Catarina, o estudo de Previatti e Souza $(2007){ }^{19}$ sobre essa prática a partir de uma visão de 20 mulheres, revelou que a maioria delas não teve seu direito de escolha preservado e foi desrespeitada sua integridade corporal.

Quanto ao contato pele a pele no primeiro minuto de vida, $95,4 \%$ das puérperas puderam ter esse contato precoce com seus bebês. A frequência apresenta-se elevada e demonstra a aplicação dessa recomendação categoria A pela OMS. Nos indicadores da maternidade deste estudo ${ }^{17}$ foi verificada uma taxa de $83 \%$ no mês de julho de 2016. Assim, esta pesquisa, apesar de não ter englobado a totalidade das puérperas assistidas na instituição, apresenta um dado motivador quanto ao aumento dessa taxa também nos meses de agosto e setembro de 2016.

Em relação ao aleitamento materno na primeira hora de vida, $71,8 \%$ das mulheres relataram ter tido essa oportunidade. As Diretrizes (2017) destacam o estímulo do início precoce da amamentação, sendo ideal já durante a primeira hora de vida. De acordo com os indicadores da maternidade, em julho de 2016 esse valor foi de 83\%. D'Artibale e Bercini $(2014)^{20}$ relataram em seu estudo, em uma maternidade do Paraná com 16 participantes, que esse contato precoce entre a mulher e neonato logo após o parto proporciona um momento único, estimulando o vínculo desse binômio e sensações prazerosas que tiram o foco da puérpera da experiência da dor do parto.

Com referência ao reconhecimento do profissional que prestou assistência ao parto, $81,8 \%$ das mulheres relataram terem sido assistidas por médicos e $94,5 \%$ por enfermeiros. Contudo, de acordo com os indicadores da maternidade, em julho de 2016, apenas $25 \%$ dos partos foram assistidos pelo profissional enfermeiro. No entanto, o registro da maternidade se refere apenas ao momento do parto e provavelmente as mulheres identificaram esses profissionais ao longo do trabalho de parto e parto, o que pode ter gerado essa diferença. Assim, faz-se necessário maior atenção quanto à identificação profissional frente a essas mulheres no atendimento ofertado.

Quanto ao partograma, 98,1\% das mulheres possuíam este documento preenchido em seus prontuários. A OMS classifica o uso do partograma como uma prática de categoria A. O estudo de Barros e Veríssimo (2011) ${ }^{21}$ sobre a frequência dessa prática, realizado em duas maternidades escola públicas em Alagoas, verificou que de 171 prontuários analisados, apenas $42 \%$ possuíam partogramas preenchidos. O índice de adesão a essa prática estimula a reflexão, já que esse recurso possibilita a análise da evolução do parto a partir da dilatação cervical e a descida de apresentação do feto de acordo com o tempo. Por meio disso é possível um acompanhamento objetivo de todo o processo, contribuindo assim com uma melhor assistência e com redução da morbimortalidade materna e fetal. ${ }^{22}$

Relacionado à satisfação das puérperas com o atendimento ofertado pela maternidade, apenas uma não se considerou satisfeita, o que demonstra elevado grau de contentamento pela assistência. No que se refere à classificação do atendimento, $65,4 \%$ das puérperas indicaram a assistência como excelente. Esses dados são bastante contrastantes se comparados a outros estudos semelhantes desenvolvidos no país. A dissertação de Baldisserotto $(2015)^{23}$, que utilizou os dados referentes à região Sudeste da pesquisa "Nascer no Brasil", revelou que somente $37,3 \%$ da população estudada (4102 mulheres) consideraram o atendimento como excelente. Estes dados reforçam que a implantação das boas práticas vem tendo sucesso na Maternidade da pesquisa, refletindo no resultado de satisfação das mulheres, podendo ser modelo para outras instituições.

A aplicação do questionário por apenas uma pesquisadora possibilitou a homogeneidade da condução das perguntas e das explicações quanto a dúvidas e questionamentos da população estudada. A pesquisadora não faz parte do quadro de funcionários da Maternidade, e, portanto, não está envolvida na assistência, o que evita o viés de cortesia. Além disso, as entrevistas eram realizadas em até 72 horas após o parto, facilitando a lembrança da puérpera quanto ao atendimento recebido. No entanto, a pesquisa teve limitações como o curto período de dois meses de coleta e o método apenas quantitativo.

\section{CONCLUSÃO}

Os dados obtidos demonstram que a maioria das mulheres tiverem seus direitos legais respeitados, acesso às boas práticas de assistência ao parto e nascimento e oferta de medidas não farmacológicas para dor, refletindo em altas taxas de satisfação com a assistência recebida. Esses resultados também possibilitam a reflexão de questões que ainda necessitam de ajustes na busca pelo aprimoramento do atendimento humanizado, como a oportunidade de visita e escolha da maternidade, utilização da manobra de Kristeller e escolha da posição durante o $2^{\circ}$ estágio do parto. Ademais, são necessários estudos englobando populações maiores em diferentes contextos que reflitam o mais próximo possível a realidade da assistência obstétrica ofertada no Brasil. 


\section{REFERÊNCIAS}

1. Domingues RM, Santos EM, Leal MC. Aspectos da satisfação das mulheres com a assistência ao parto: contribuição para o debate. Cad Saude Pública. 2004;20 Supl 1:S52-S62.

2. Rattner D. Humanização na atenção a nascimentos e partos: breve referencial teórico. Interface: Comunicação, Saúde, Educação. 2009;13 (Supl 1):595-602.

3. Brasil. Ministério da Saúde. Secretária de Ciência, Tecnologia e Insumos Estratégicos. Comissão Nacional de Incorporação de Tecnologias no SUS. Diretriz Nacional de Assistência ao Parto Normal [Internet]. Brasília: Ministério da Saúde; 2016 [acesso em: 6 abr 2016]. Disponível em: http://conitec.gov.br/images/ Consultas/2016/Relatorio_Diretriz-PartoNormal_CP.pdf

4. Ribeiro LB. Nascer em Belo Horizonte: cesarianas desnecessárias e prematuridade [dissertação]. Belo Horizonte: UFMG; 2016.

5. Brasil. Universidade Aberta do SUS (UNA-SUS). Declaração da OMS sobre taxas de cesáreas [Internet]. Brasília: UNA-SUS; 2015 [acesso em: 16 out 2016]. Disponível em: https://www.unasus.gov. br/noticia/declaracao-da-oms-sobre-taxas-de-cesareas

6. Organização Mundial da Saúde. Declaração da OMS sobre taxas de cesáreas [Internet]. Genebra: OMS; 2015 [acesso em: 18 out 2016]. Disponível em: https://apps.who.int/iris/bitstream/ handle/10665/161442/WHO_RHR_15.02_por.pdf;jsessionid=515F DFB4F7480E12039EEC95550E6F94? sequence=3.

7. Brasil. Maternidade Escola Assis Chateaubriand. Rede Cegonha [Internet]. Maternidade Escola Assis Chateaubriand, 2016 [acesso em: 3 abr 2016]. Disponível em: http://www.ebserh.gov.br/web/ meac-ufc/rede-cegonha

8. Brasil. Maternidade Escola Assis Chateaubriand. Ministério da Saúde reconhece a MEAC como Centro de Apoio em Boas Práticas [Internet]. Fortaleza: Maternidade Escola Assis Chateaubriand; 2016 [acesso em: 18 out 2016]. Disponível em: http://www.ebserh.gov. $\mathrm{br} / \mathrm{web} / \mathrm{meac}-$ ufc/noticias/-/asset publisher/JYdUOrTtibK1/content/ $\mathrm{id} / 1381908 / 2016-08$-ministerio-da-saude-reconhece-a-meac-comocentro-de-apoio-em-boas-praticas

9.Organização Mundial da Saúde. Boas práticas de atenção ao parto e ao nascimento [Internet]. Genebra: Organização Mundial da Saúde; 1996 [acesso em: 5 nov 2016]. Disponível em: http://static.hmv.org. br/wp-content/uploads/2014/07/OMS-Parto-Normal.pdf

10. BrasiL. Ministério da Saúde. Secretaria de Ciência, Tecnologia e Insumos Estratégicos. Diretrizes Nacionais de Assistência ao Parto Normal [Internet]. Brasília: Ministério da Saúde; 2017 [acesso em: 5 ago 2017]. Disponível em: http://bvsms.saude. gov.br/bvs/publicacoes/diretrizes_nacionais_assistencia_parto_ normal.pdf

11. Brasil. Lei ${ }^{\circ} 11.108$, de 7 de abril de 2005. Altera a Lei no 8.080, de 19 de setembro de 1990, para garantir às parturientes o direito à presença de acompanhante durante o trabalho de parto, parto e pós-parto imediato, no âmbito do Sistema Único de Saúde - SUS [Internet]. Brasília; 2005 [acesso em: 5 nov 2016]. Disponível em: https://www.planalto.gov.br/ccivil_03/_Ato2004-2006/2005/Lei/ L11108.ht6m

12. Davim RN, Torres GV, Dantas JC. Efetividade de estratégias não farmacológicas no alívio da dor de parturientes no trabalho de parto. Rev Esc Enferm USP. 2009;43(2):438-45.

13. Silva AL, Nascimento ER, Coelho EA. Práticas de enfermeiras para promoção da dignificação, participação e automonia de mulheres no parto normal. Esc Anna Nery. 2015;19(3):424-31.

14. Porto AM, Amorim MM, Souza AS. Assistência ao primeiro período do trabalho de parto baseada em evidências. Femina. 2010;38(11):527-37.

15. Brasil. Portaria $n^{0} 1067$ de 4 de julho de 2005. Ministério da Saúde institui a Política Nacional de Atenção Obstétrica e Neonatal [Internet]. Brasília; Ministério da saúde; 2005 [acesso em: 5 nov 2016]. Disponível em: http://www.lex.com.br/doc 395287 PORTARIA_N_1067_DE_4_DE_JULHO_DE_2005.aspx

16. Motta SA, Feitosa DS, Bezerra ST, Dodt RC, Moura DJ. Implementação da humanização da assistência ao parto natural. Rev Enferm UFPE online. 2016;10(2):593-9.

17. Brasil. Relatório assistencial da Maternidade Escola Assis Chateaubriand (MEAC): 2015 [Internet]. Fortaleza: Maternidade Escola Assis Chateaubriand/Hospitais Universitários/UFC/ Ebserh; 2016 [acesso em: 18 out 2016]. 169 p. Disponível em: http://www.ebserh.gov.br/documents/214336/0/ Relat\%C3\%B3rio+MEAC+2015+final.pdf/389f7aa6-2c8a-42cd$8550-59$ ba2297733f

18. Sousa AM. Práticas obstétricas na assistência ao parto e nascimento em uma maternidade de Belo Horizonte [dissertação]. Belo Horizonte: UFMG; 2013.

19.Previatti JF, Souza KV. Episiotomia: em foco a visão das mulheres. Rev Bras. Enferm. 2007;60(2):197-201.

20. D’Artibale EF, Bercini LO. O contato e a amamentação precoce: significados e vivências. Texto Contexto Enferm. 2014;23(1):109-17.

21. Barros LA, Veríssimo RC. Uso do partograma em maternidades escola de Alagoas. Rev Rene. 2011;12(3):555-60.

22.Rocha IM, Oliveira SM, Schneck CA, Riesco ML, Costa AS. O partograma como instrumento de análise da assistência ao parto. Rev Esc Enferm USP. 2009;43(4):880-8.

23. Baldisserotto ML. Associação entre as boas práticas de assistência ao trabalho de parto e parto e a avaliação pelas puérperas do cuidado recebido [dissertação]. Dissertação apresentada à Escola Nacional de Saúde Pública Sergio Arouca (ENSP/Fiocruz). Rio de Janeiro: Fundação Oswaldo Cruz; 2015.

\section{Como citar:}

Azevedo AS, Moreira MA, Sabry SD, Pessoa UM, Carvalho EM, Nascimento SL. Percepção de puérperas quanto às boas práticas de assistência ao trabalho de parto e parto. Rev Med UFC. 2020 jan-mar;60(1):28-34. 